\title{
A NEW CONCEPTUAL MODEL FOR THE STRUCTURAL PROPERTIES OF CHAR PRODUCED DURING VEGETATION FIRES
}

\author{
Heike KNICKER ${ }^{1}$, André HILSCHER ${ }^{1}$, Francisco J. GONZÁLEZ-VILA ${ }^{2}$ and Gonzalo \\ ALMENDROS $^{3}$
}

1. Lehrstuhl für Bodenkunde, Technische Universität München, 85350 Freising-Weihenstephan

2. Instituto de Recursos Naturales y Agrobiología de Sevilla, CSIC, PO Box 1052, 41080 Sevilla, Spain. 3. Centro de Ciencias Medioambientales, CSIC, Serrano 115B, 28006 Madrid, Spain

After vegetation fires considerable amounts of charred necromass are incorporated into soils and sediments. To elucidate its role in geobiochemical cycles a good understanding of its chemistry is crucial. Although several models describing char on a molecular level are reported in the literature (Schmidt \& Noack, 2000), a commonly accepted view of the chemistry involved in Black Carbon (BC) production during vegetation fires is still missing. Therefore, the intention of the present work was to obtain some insights into structural properties of char produced during biomass burning by comparing results obtained from controlled charring experiments, the analysis of naturally charred soil organic matter with the pyrolysis literature.

Our studies indicate that the aromatic skeleton of char accumulating after a vegetation fire must contain remains of the lignin backbone and considerable contributions of furans and anhydrosugars from thermally altered cellulose. Since heating of vegetation residues leads to little changes of their $\mathrm{C} / \mathrm{N}$ ratios in the charred product, $\mathrm{N}$ must be incorporated into structures which are fairly resistant to heating. Solid-state ${ }^{15} \mathrm{~N}$ NMR spectroscopy identified them as mostly pyrrole/indole-type $\mathrm{N}$ with minor contribution of pyridine N. Depending on the source material, The $\mathrm{C} / \mathrm{N}$ ratios of char can be as wide as 440 to 630 for burnt woody material but also as narrow as 6.0 to 6.9 as it was found for char from for young grass material. Accordingly, in non-woody chars, N-heteroaromatic structures can consume up to $17 \%$ and sometimes even $60 \%$ of their organic C. Although they comprise considerable portions of charred organic matter, this "Black Nitrogen" is still mostly neglected in the BC discussion.

Our results clearly demonstrate that for residues after vegetation fires, char models assuming a graphite-like structure are oversimplified. Therefore, a new structural concept for char formed due to vegetation fires is proposed. According to this concept, char can be seen as a heterogeneous mixture of thermally altered biomolecules, the alteration degree of which is dependent upon the severity of the fire and the chemistry of the original vegetation. Thus, only intensively charred material reveals an entirely aromatic structure, whereas alkyl-C 
content increases in chars produced at moderate temperature. With respect to elemental analysis $\mathrm{N}, \mathrm{O}, \mathrm{S}$ substitutions are common features of the charring products.

The present concept implies that the chemical composition of char can vary to a great extent and that those differences are likely to determine the recalcitrance of char. Being less graphite-like but containing $\mathrm{N}, \mathrm{O}$ and $\mathrm{S}$ substitutions, such char would allow for fast oxidation, facilitating further microbial attack and dissolution in the soil solution. Although, relative to litter, char degradation is supposed to be slow, on long-term and under oxic conditions this process may alter char to an extent that it becomes indistinguishable from naturally formed organic matter in soils and sediments. Oxygen-depletion or environments with low microbial activity may be necessary for pyrogenic residues to survive without major chemical alterations and in considerable amounts for millennia and longer.

The high chemical heterogeneity of char and a low contribution of highly condensed polyaromatic structures can also explain the uncertainties with respect to its detectability in soils and sediments with some common degradative approaches (Masiello, 2004). Depending on the source, the portion of $\mathrm{BC}$ that survives the harsh chemical and thermal degradation procedures used for BC identification varies. On the other hand, biomarker approaches relay on the identification of degradation products from polyaromatic clusters (Glaser et al., 1998). In chars produced at lower temperatures, those clusters, represent only a small fraction that cannot account for the total char content of the respective soil or sediment.

\section{REFERENCES}

Glaser B., Haumaier L., Guggenberger G. and Zech W. (1998) Black carbon in soils: the use of benzenecarboxylic acids as specific markers. Organic Geochemistry 29, 811-819.

Masiello C.A. (2004) New directions in black carbon organic geochemistry. Marine Chemistry 92, 201-213.

Schmidt M.W.I. and Noack A.G. (2000) Black carbon in soils and sediments: analysis, distribution, implications, and current challenges. Global Biogeochemical Cycles 14, 777 793. 